\title{
E Pluribus Unum: Using Conceptual Metaphor Theory to Explore and Support Mixed-Ability Workplaces
}

FRANCESCO CAFARO, Indiana University-Purdue University Indianapolis, United States

ERIN BRADY, Indiana University-Purdue University Indianapolis, United States

SOWMYA CHANDRA, Indiana University-Purdue University Indianapolis, United States

ULKA PATIL, Indiana University-Purdue University Indianapolis, United States

ABHIJEET SAXENA, Indiana University-Purdue University Indianapolis, United States

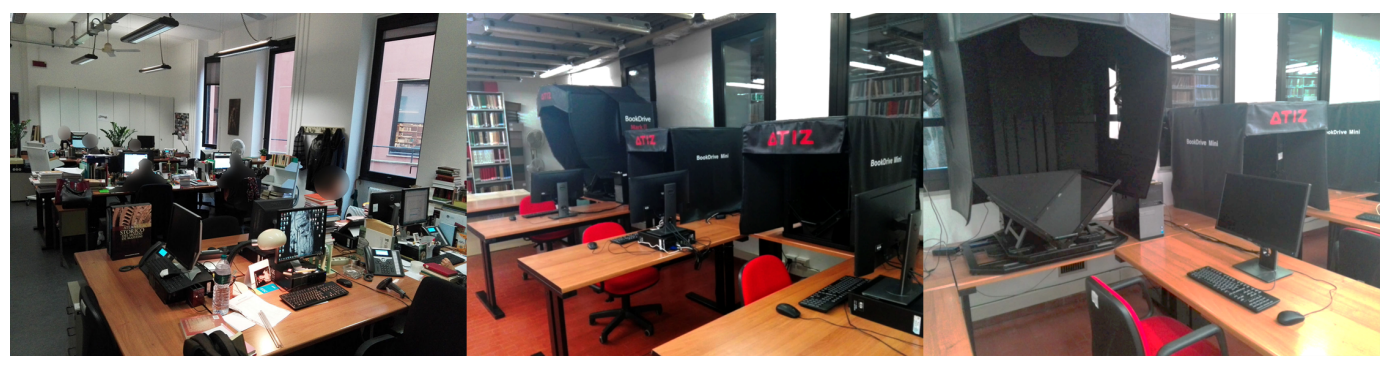

Fig. 1. Catalog office at the university library and detailed view of the Digitization Lab and of the scanners that the mixed-ability workers that we interviewed used to digitize books and documents

Even when they are able to secure employment, people with cognitive disabilities typically encounter significant difficulties in the workplace. In this paper, we focus on Mixed-Ability workplaces: work settings in which people without disabilities and with different types of disabilities collaborate on a daily basis. The case study for our exploratory research is a university library that has been able to support a mixed-ability work setting for over four years. We describe how a theory from cognitive linguistics (Conceptual Metaphor Theory) can be used to explore the challenges that people encounter in mixed-ability workplaces, identify the cognitive processes that differ between neurotypical team leaders and workers with cognitive disabilities, and translate these findings into design recommendations for embodied technologies that support mixed-ability workplaces.

CCS Concepts: • Human-centered computing $\rightarrow$ Empirical studies in HCI; Interaction techniques; User studies; Accessibility theory, concepts and paradigms; Empirical studies in accessibility.

Additional Key Words and Phrases: Mixed-Ability Workplaces; Embodied Interaction; Embodied Cognition; Conceptual Metaphor Theory; Tangible Interaction; Design; Libraries

Authors' addresses: Francesco Cafaro, fcafaro@iu.edu, Indiana University-Purdue University Indianapolis, 535 W. Michigan Street, Indianapolis, Indiana, 46202, United States; Erin Brady, brady@iupui.edu, Indiana University-Purdue University Indianapolis, 535 W. Michigan Street, Indianapolis, Indiana, 46202, United States; Sowmya Chandra, sowchan@iu.edu, Indiana University-Purdue University Indianapolis, 535 W. Michigan Street, Indianapolis, Indiana, 46202, United States; Ulka Patil, ulpatil@iu.edu, Indiana University-Purdue University Indianapolis, 535 W. Michigan Street, Indianapolis, Indiana, 46202, United States; Abhijeet Saxena, absaxena@iu.edu, Indiana University-Purdue University Indianapolis, 535 W. Michigan Street, Indianapolis, Indiana, 46202, United States.

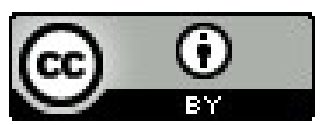

This work is licensed under a Creative Commons Attribution International 4.0 License.

(C) 2021 Copyright held by the owner/author(s).

2573-0142/2021/10-ART384. https://doi.org/10.1145/3479528

Proc. ACM Hum.-Comput. Interact., Vol. 5, No. CSCW2, Article 384. Publication date: October 2021 


\section{ACM Reference Format:}

Francesco Cafaro, Erin Brady, Sowmya Chandra, Ulka Patil, and Abhijeet Saxena. 2021. E Pluribus Unum: Using Conceptual Metaphor Theory to Explore and Support Mixed-Ability Workplaces. Proc. ACM Hum.-Comput. Interact. 5, CSCW2, Article 384 (October 2021), 31 pages. https://doi.org/10.1145/3479528

\section{INTRODUCTION}

People with cognitive disabilities encounter significant difficulties in the workplace $[1,10]$, consistently reporting lower employment and pay than people without disabilities, and more part-time and low-wage employment [44]. For example, in the U.S., unemployment among people with Autism is estimated to be around 50-75\% [19].

Even people with disabilities that are able to secure employment in mixed-ability workplaces (i.e., traditional work settings in which workers without disabilities and with different types of disabilities collaborate) often encounter significant misunderstandings or negative attitudes from their coworkers [10]; this impacts their ability to be productive and even to learn the skills required for their profession [70].

Part of the problem is that people in mixed-ability workplaces see their life, challenges, and work from different perspectives [60]. These differences may be then reflected in the actions that they do when they collaborate with each other and interact with the technologies that support their work If this plurality of perspective is made visible to people in the workplace and is supported by useful and intuitive technologies, however, it can provide an invaluable resource for work settings. This is the major motivation of the work that we report in this paper.

Embodied cognition [75] and, in particular, Conceptual Metaphor Theory (CMT) [36, 48] provide a theoretical framework to dig into people's cognitive processes and unveil this plurality of perspectives. The overarching idea of embodied cognition is that our body plays a fundamental role in our cognitive process: we make sense of what is around us because of our physical interaction with the world. Conceptual Metaphor Theory (CMT) posits that we acquire basic mental patterns (e.g., the concepts of UP/DOWN, NEAR/FAR, or BALANCE) at a very early stage of our lives. These mental patterns are called "embodied schemata" and arise through repeated patterns in our bodily interaction with the world [36]. Because, as humans, we share similar bodily experiences, embodied schemata may provide a shared vocabulary for the design of novel technologies that feel "intuitive" to many people [30]. For this reason, embodied schemata have been successfully used as ingredients for designing "intuitive," "novel" technologies, including embodied interactions $[22,28]$ that facilitate children's learning of music [4], tangible user interfaces [34] to control billing software at a German beverage company [32], and touch-screen based audio entertainment applications [33].

As Hurtienne also noted, however, CMT has potential beyond the design of "intuitive" interfaces: it could facilitate the creation of more "inclusive" technologies, because embodied schemata should be "near universal across cultures and age groups" [30]. There is, however, a lack of studies that "go beyond age comparisons and include users who differ in specific capabilities (sensory, motor, and cognitive)" [30], and studies have shown that metaphors are be used and interpreted differently by neurotypical and neurodiverse people [9, 38, 40, 41].

In the exploratory study that we describe in this paper, we conducted a week of observations followed by semi-structured interviews at a university library that has been able to successfully maintain a mixed-ability workplace for over four years - see Figure 1 . We use this case study to illustrate how CMT can be applied in a new context (i.e., mixed-ability workplaces), to identify common and divergent mental patterns that mixed-ability workers use when describing their tasks and work practices. Commonalities can inform the design of "intuitive" user interfaces, while 
divergences may highlight much needed points for connection that can increase the "inclusiveness" of technologies and workplaces.

In order to illustrate how CMT-based approaches to design need to be adapted to mixed-ability workplaces, we structured our paper on the premise that "the best way to talk about methods is to show instances of the actual work" [37]. This style of talking about methods is inspired by Interaction Analysis [37], a different methodological approach that seeks to understand the interconnection between people's utterances and gestures.

In the next sections, we describe the mixed-ability structure that we observed at the partner library, followed by an overview of background and related work. Next, we describe by examples how to collect data for CMT in the context of mixed-ability workplaces, how to code data from interviews and contextual inquiry sessions, and how to use data coded with CMT to identify commonalities and divergences among communities of workers. Finally, we discuss how these findings can inform the design of technologies and interfaces that support mixed-ability work.

\section{CASE STUDY: MIXED-ABILITY WORK AT A UNIVERSITY LIBRARY}

We partnered with a university library in Italy to conduct exploratory research aimed at understanding how people with cognitive disabilities are integrated into the workforce.

\subsection{Disability Hiring Policies in Italy and the Peculiarity of the Partner Site}

People with disabilities may be more present in the workforce in Italy (when compared to other countries, e.g., U.S.), which has disability-specific hiring quotas requiring at least $7 \%$ of employees at large companies to be people with disabilities. Our library partner, however, offered a particularly interesting case because its directors have explicitly hired library workers with physical and cognitive disabilities for the past four years and far beyond the required quotas (currently, nearly a quarter of their employees are people with disabilities). Typical tasks include cataloging books so that they can be easily found, acquiring new resources, organizing community events, interfacing with people, and keeping technologies (e.g., touchscreens, tablets) up and running.

\subsection{The Digitization Project and the Role of External Personnel}

During our stay at the partner site, we focused on exploring the dynamics of one specific project: the Digitization Project.

The library partners with two different external non-profit organizations (both are structured as co-ops -in Italian, "cooperativa") to recruit workers with cognitive and physical disabilities for tasks that are currently under-staffed, or that not enough library employees are willing to do. These workers are primarily stationed in the library's "digitization lab," where they use scanners to create digital versions of books and manuscripts (ranging from the XVI century to modern paperback editions) -see Figure 1. Workers from the first non-profit come in during the morning hours, and are replaced by workers from the second non-profit in the afternoon who take over a specific scanner station. All the external workers have different types of cognitive disabilities, and are supervised by a neurotypical team leader, who is also an external contractor. In turn, the team leader reports to a project manager who is a direct library hire, and who works for the director of the Catalog office of the library.

The workers who participated in this study suffer from different types of cognitive disabilities (including anxiety disorders and autism) and have different roles in the library scanning process. We associated the interviewees with their roles: P1 was the neurotypical team leader, $\mathrm{P} 2$ was the worker at the post-processing station (who was tasked, for example, with tilting and correcting the images acquired from the scanner), $\mathrm{P} 3$ and $\mathrm{P} 4$ were at the scanner stations (generating digital images of books and manuscripts), and P5 performed data-entry work (e.g., inputting the book 


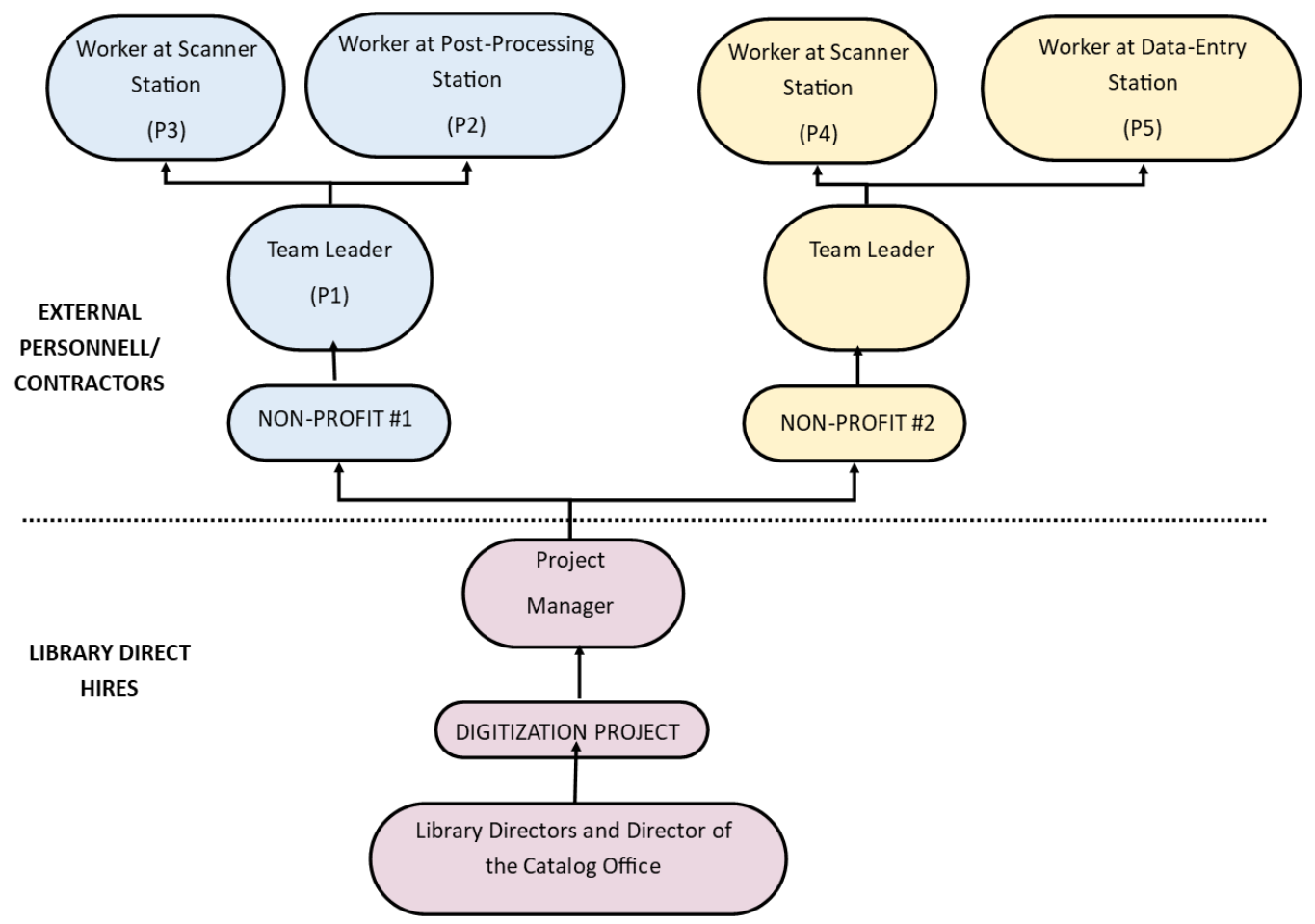

Fig. 2. Inside-out organization chart of the Digitization Project. People working for the library are in purple, while the external workers from the two non-profit organizations are in blue and yellow, respectively.

title in a database). They all collaborated in some ways with each other, especially with their team leader. An organization chart of the Digitization Project is illustrated in Figure 2.

While some of the full-time library staff are also involved in the digitization process, the digitization lab is in a separate physical space from the main Catalog office of the library, so opportunities for spontaneous interactions with full-time staff are limited.

\section{BACKGROUND AND RELATED WORK}

In this section, we provide relevant background and introduce related work that set the stage for the study and analysis that we discuss in this paper. First, we review literature on disability in the workplace, in order to highlight challenges and opportunities for mixed-ability workplaces. Second, we further describe the theory of Conceptual Metaphors with a particular focus on how it has been used to inform the design of "intuitive" embodied interactions.

\subsection{Neurodiversity}

Our work looks at the experiences of neurodiverse employees in the workplace. Silberman defines neurodiversity as:

"the notion that conditions like autism, dyslexia, and attention-deficit/hyperactivity disorder (ADHD) should be regarded as naturally occurring cognitive variations with distinctive strengths that have contributed to the evolution of technology and culture rather than mere checklists of deficits and dysfunctions." [67] 
In our work, we apply this definition of neurodiversity to specifically focus on people with varying developmental, cognitive, and learning abilities. We use the language of neurodiverse to indicate people with conditions like Autism, ADHD, and mental illness [56], and neurotypical to indicate people without these types of conditions.

Importantly, neurodiverse individuals may have different cognitive frames of reference or styles of thinking [16]. While these differences historically may have been seen as deficits, they also have unique "upsides" [5] -for example, people with Autism may have higher visuospatial skills than neurotypical people [57]. These alternative styles of thinking impact how neurodiverse and neurotypical individuals can collaborate or exchange ideas [8], and the perspectives of neurodiverse people are often ignored or misunderstood by neurotypical people [68].

\subsection{Challenges and Opportunities for Mixed-Ability Workplaces}

3.2.1 Disability in the Workplace. People with disabilities in the United States have a high unemployment rate and experience discrimination and pay disparities [1, 44]. Even after securing employment, people with disabilities often encounter barriers to communicating and collaborating with their coworkers or managers [61, 62]. Traditional employment programs for people with disabilities often use the model of sheltered workplaces, where the work environment is specifically designed for people with a specific disability to do individualized, repetitive tasks. People with disabilities in mixed-ability workplaces (i.e. settings in which workers without disabilities and with different types of disabilities collaborate), on the other hand, often encounter significant misunderstandings or negative attitudes from their coworkers [10].

Many workplaces employ technologies which facilitate collaboration but are inaccessible to employees with disabilities [10]. For example, many people with visual impairments use screenreaders which read aloud text on their computer screen. However, documents exchanged in the workplace may not be screen-reader compatible -for example, PDFs are inaccessible unless the authors explicitly add in accessibility annotations. Additionally, the use of assistive technologies may interfere with other workplace tasks -Branham and Kane note how employees who use screenreaders are unable to simultaneously listen to a presenter while their screenreader dictates related visual content, like PowerPoint slides [10].

Recent work at CHI [49] and CSCW [74] has continued to explore how people with disabilities collaborate with their coworkers or clients, but there remain a number of contexts in which we do not have a robust understanding of the collaborative technologies used in mixed-ability workplaces.

3.2.2 Workplace Cultures and Collaborative Practices. Accessibility in the workplace is not a static set of accommodations, but a complex and dynamic process of identifying and resolving access issues. As a result, one of the most significant factors which impact work experiences for people with disabilities are social, rather than technical accessibility barriers [66]. These barriers may arise from coworkers and managers without disabilities who misunderstand their disabled colleagues' abilities [10,21], or from employees with disabilities who fear being judged based on their use of assistive technologies [65]. The corporate and social culture of a workplace plays a significant role in how people with disabilities are accepted, and how likely they are to receive the accommodations that they need to be successful [61].

Recent papers at ASSETS [7] and CSCW [74] have begun to unpack the social processes through which collaborators with and without disabilities negotiate their access needs, and work at $\mathrm{CHI}$ has examined accessible collaborative cultures and practices in diverse settings, such as higher education [43] and recreational activities [17].

3.2.3 Invisible Work. In their study of collaboration between visually impaired and sighted coworkers, Branham and Kane [10] identified numerous examples of invisible work performed by people 
with disabilities to make their workplace accessible to them, and gain assistance as needed. Employees with disabilities may also feel the need to hide or manage their use of assistive technologies out of fear of judgment [65]. While this invisible work is less-studied, it is crucial for understanding the ways in which people with disabilities engage in collaboration in the workplace.

\subsection{Designing Embodied Interactions using Conceptual Metaphor Theory (CMT)}

3.3.1 Embodied Cognition. Our work is inspired by the theory of Embodied Cognition [75]. Embodied Cognition is based on the seminal works of Heidegger's [26] and Merleau-Ponty's phenomenology [55], and on Piaget's constructivism [58]. According to embodied cognition, our body plays a fundamental role in our cognitive processes: our discoveries happen thanks to the interaction between our body and the surrounding environment [64]. Experimentally, embodied cognition is based on a multidisciplinary array of observations in the fields of neuroscience and cognitive linguistics. For example, McNeill [54] reports that gesturing while speaking facilitates communication. In a study using magnetic resonance, Dreyer et al. [23] report that our left sensory-motor cortex is activated when we process abstract concepts such as "love," while lesions on the hand motor cortex may impair patients' ability to process concrete tool nouns.

3.3.2 Conceptual Metaphor Theory and Embodied Schemata. In particular, this work is grounded on Lakoff's and Johnson's Conceptual Metaphor Theory (CMT) [36, 48]. According to this theory, we acquire basic mental patterns (embodied schemata) at a very early stage of our lives, through our bodily interaction with the world [36]. Embodied schemata then arise from repeated bodily experiences, such as an external FORCE experience, or through seeing or feeling physical and visual ATTRIBUTES. They materialize as a meaningful "recurrent pattern, shape, and regularity in our daily body experience" ( [36], p. 29). For example, a baby learns the BALANCE schema when they are able to stand in an erect position [36]. Through time, this schema evolves metaphorically, creating complex networks of mental connections [48] -so we can, for example, apply the idea of BALANCE to abstract domains, such as social justice and architecture.

Embodied schemata operate as conceptual primitives that help us lay the conceptual foundation of our reasoning. For example, Gentner [25] reports that people typically reason about electricity using either a WATER-FLOW or a MOVING CROWD model. In the first case, an electric current is understood as water flowing through a pipe; in the latter case, individuals' movement through passageways and small gates. In general, people reasoning according to the WATER-FLOW model, perform better on battery problems, while those using the MOVING CROWD metaphor excel on resistor problems. Thus, these mental patterns structure (and, potentially, alter) our reasoning.

3.3.3 Embodied Interaction. Our technological focus is on embodied interaction [22, 28]. The concept of embodied interaction was established through the seminal book of Paul Dourish [22]. According to Dourish, meaningful interaction is formed through the interplay between the phenomenon and social, material, and bodily practices. In later work, Hornecker [28] focuses on the role of the body in embodied interaction, arguing, for example, that "movement and perception are tightly coupled." Along these lines, the term "full-body Interaction" has also been used to denote an "input method" in which people interact with computer systems using hand gestures and body movements [14].

3.3.4 CMT for Designing "Intuitive" Embodied Interactions. CMT has been used by Antle et al. [4] to inform the design of a full-body installation that facilitates the learning of musical concepts: input actions (i.e., gestures and body movements) are mapped into perceptual, auditory feedback. In general, as documented by Hurtienne in [30], CMT has been used to inform the design of novel interactive interfaces, and to evaluate and critique existing ones (e.g., [45]). Hurtienne and

Proc. ACM Hum.-Comput. Interact., Vol. 5, No. CSCW2, Article 384. Publication date: October 2021. 
Israel [31] describe one of the first attempts to apply this theory to the design of Tangible User Interfaces [34]. Their noteworthy work lists a table of categories of body experiences (Space, Containment, Multiplicity, Force, Attribute, Process, Surface, and Basic), and the corresponding embodied schemata that belong to each of those categories (e.g., up-down, container, merging, diversion, big-small, matching, substance, etc.) [31]. Although Hurtienne's work does not provide definitions for each schema and does not focus on work settings, the table in [31] provided the starting point for the coding dictionary that we used in our analysis. In a similar context (the design of tangible user interfaces), Macaranas et al. [53] conducted a study in which participants were asked to map Space and Attribute schemata to different pairs of physical objects.

In general, current work on designing with CMT aims at crafting intuitive (i.e., "systems that can be used by subconsciously applying prior knowledge" [29]), innovative (i.e., that go beyond the state of the art), and inclusive (across different age groups) interfaces [30]. In closely related work [33], Hurtienne outlines a design process that researchers used to work with a software development team (including product manager, software engineer, and visual designer) to design and prototype a touch-screen interface for a sound entertainment system. The design process included conducting 1 hour contextual interviews at eight participants' homes (from a "rather homogeneous target group" [30]), followed by a round of coding for embodied schemata and metaphors on the transcripts. Except for the first interview, the others were split among the research team members. The process then moved to create affinity diagrams with additional notes (not coded with CMT) that refer to user problems and needs. It ended with the creation of paper and functional prototypes that included design elements that the team deemed as based on the embodied schemata and metaphors that were identified during the design work (e.g., radio stations were represented as a SURFACE) [33]. Although this CMT-based design approach is similar in concept with the work that we describe in this paper, it needs to be fundamentally altered to explore mixed-ability workplaces for three major reasons. Specifically:

- Data Collection Process. First, we cannot immediately perform short (1 hour) contextual inquiry sessions to collect participant's remarks: we need to first develop trust [35] and equal relationships [12] with neurodiverse participants.

- Commonalities and Divergences. Second, because we include different communities of mixedability workers (rather than homogeneous groups), we are not only seeking commonalities, but also divergences in the ways in which workers use schemata to describe tasks and work practices.

- Coding by Idea Units. Third, because our focus is on work processes and inclusiveness (and not solely on designing "intuitive," 1:1 mappings between schemata and interface elements), we think it is more appropriate to code transcripts by idea units [2], rather than by keywords (like "in/out" or "up/down"). In other words, we need to go beyond simple, literal mappings between keywords and interface elements. This, in turn, requires additional attention to the inter-coder reliability: the validity of the coding process does not come from a standardized list of keywords, but from cross-validation and discussion among multiple coders. For this reason, we cannot easily split the dataset among researchers, but we need to develop a rigorous process to discuss and resolve disagreement.

\section{METHODS, I.E. HOW TO COLLECT DATA FOR CMT ANALYSIS IN MIXED-ABILITY WORKPLACES}

The overarching aim of this work was to conduct exploratory research on a mixed-ability workplace (a university library in Italy) using the lenses of Conceptual Metaphor Theory (CMT). Because of the complexity of mixed-ability settings and the cognitive differences between workers, however, 
we could not simply use existing approaches on designing with embodied schemata, which are typically based on short contextual inquiry sessions or interviews [33].

Rather, we drew from CSCW's long history of embedded fieldwork [59] to plan our data collection visit to the site. We began by developing relationships with the team at the library site. We conducted an initial virtual meeting with the library director and program leader to learn about the structure of their program and identify opportunities for us to perform observations. In the weeks before our visit, we had a larger meeting with the director, program leader, four members of the library staff, and three representatives of their external partner groups focused on workers with cognitive disabilities. These meetings allowed us to anticipate potential challenges and to get a grounding in the work being done before arriving at the site.

Additionally, since many of the workers in the digitization lab are people with disabilities, we incorporated established techniques for developing trust [35] and equal relationships [12] with disabled participants. We created an introductory video which the program leader played for the neurodiverse workers, introducing ourselves in Italian and explaining our roles and what kinds of things we would be doing during our visit. We tailored our script for this video to be easily understandable and welcoming.

The primary data collection spanned a week in Fall 2019. Two researchers met each of the library staff members, and situated ourselves into the digitization lab to ensure that the digitization lab workers had time to grow comfortable with our presence so we would not be disruptive to their work. We combined observations, semi-structured interviews, and contextual inquiry to learn about the digitization tasks being performed. On the last day at the digitization lab, we agreed with the team leader that the neurodiverse workers were familiar enough with the researchers, and we audio-recorded a set of semi-structured interviews. Interviews were transcribed and translated. We then used a mixed-method approach to analyze the transcripts.

While European data privacy laws limited what data we could collect about participants' disabilities, two of them were employed via the small co-op which exclusively serves people with Aspergers, while the other two were employed via a program of the larger co-op which serves individuals with intellectual disabilities. The team leader and supervisors were all neurotypical.

\section{ANALYSIS, I.E. HOW TO CODE MIXED-ABILITY WORKPLACE DATA WITH CMT}

After transcribing and translating the interviews, a team of five researchers coded the transcripts looking for instances of embodied schemata. Differently from prior work on designing with CMT (e.g., [33]), we coded our transcripts by idea units [2], rather than by keywords. Using embodied schemata and their category of body experience to code how people describe their tasks, work practices, and the technologies that they use can be a fuzzy and challenging task, because CMT has never been used in the context of mixed-ability workplaces.

Importantly, analyzing interview transcripts using CMT may be complicated in neurodiverse settings, since prior research has shown neurotypical and neurodiverse people interpret and use figurative language differently. The use of figurative language, like metaphors, involves multiple cognitive processes involving lexical and semantic abilities $[13,40]$ and neurocognitive mechanisms like executive functioning $[6,69]$. These mechanisms function differently among neurodiverse people [9], and lead to communication issues between neurotypical and neurodiverse individuals [63].

Neurotypical people often had greater success in recognizing or comprehending traditional metaphors than people with autism spectrum disorders [38, 40, 72], ADHD [9], or dyslexia [41]. But neurodiverse individuals were able to generate more metaphors [41], and metaphors which were more creative $[39,40]$, than neurotypical people.

Below, we describe the four steps of the coding process we employed to code our data. 


\subsection{Individual Coding}

We individually conducted a first round of open coding to explore major patterns or themes in the interviews. We used ad-hoc codes such as "role", "pain-point", "liking", "motivation," etc. were used to could decipher patterns and biases. This process allowed us to get more familiar with the interview transcripts, and to check the English version of the transcripts in order to resolve inconsistencies with the original Italian transcripts.

Next, three researchers individually coded each of the transcripts looking for instances of embodied schemata. For coding, we used the embodied schemata listed in multiple sources, in particular [4] and the table of embodied schemata reported by Hurtienne in [31]. We want to highlight once more that we coded the transcripts by idea units [2]: we were not looking for specific keywords, but rather for full sentences that explained the same concepts.

\subsection{Collaborative Coding and Identifying Disagreement}

The three researchers then met weekly for three weeks to compare their individual coding, discuss their interpretation, and create a single file with a mutually agreeable coded transcript. We used the cloud version of Atlas.ti (an online collaboration tool) for this round of group coding. During these discussions, there were instances of disagreement, so we used a new code, "Disagreement", to mark those instances and to discuss them. For example, in the first interview, the quote I observe the anxiety rising, growing was seen as an instance of BLOCKAGE by some, and as RESISTANCE by others. We came up with a total of 57 disagreement codes ( $15 \%$ of the 372 codes that we applied), and after we were satisfied with them, we set our meeting agendas going forward to resolve these disagreements.

\subsection{Resolving Disagreements and Creating a Dictionary}

Next, all five researchers (the three researchers that initially coded the transcripts, and two additional ones with extensive experience with embodied schemata who were not involved in the initial coding) met weekly for about two months to go through each of the interviews as a group and review each others' codes. The fact that these two researchers were not involved in the first phase of the coding is important, because they were able to participate in the discussion without having an initial bias towards their personal coding choices. We used Zoom for these research meetings, because the analysis was conducted during the COVID-19 pandemic.

During our weekly meetings, it became apparent that there were different opinions on the meanings of certain schemata. In order to create uniformity in our research we created a dictionary with a definition for each code (i.e., embodied schema) that we had used. The definitions were borrowed or adapted from the SIL glossary of linguistic terms ${ }^{1}$.

The dictionary helped us distinguish schemata that initially seemed overlapping. For example, in the dictionary, RESISTANCE was defined as involving an active force, while BLOCKAGE a passive force -hence, it allowed us to review instances that we initially coded as either RESISTANCE or BLOCKAGE and see if the action or obstacle is active or passive, and re-code it accordingly. Similarly, we agreed that REMOVAL OF RESTRAINT involves the use of an external tool to remove a BLOCKAGE, while ENABLEMENT has a more introspective connotation and can be used when workers feel that they have the skills to fulfil a task.

At the end of the discussion, if a disagreement was resolved, we used a new code "Resolved Disagreement" to indicate it, and if we wanted to further revisit the code, we coded it as "Revisit".

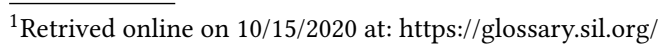




\subsection{Updating the Codes Based on the Dictionary}

With the new dictionary in place, we decided to do a third pass at the interviews, and realized that there were some instances where the codes did not fit the new definitions. We created a code called "Change" to mark those instances and bring them up for discussion during our weekly meetings. After discussion, when the five researchers agreed on these new instances, we added a new code, "Changed" to mark them for future reference.

At the end of this process, we were left with 9 instances still marked as "revisit" (thus, we had a $98 \%$ agreement on the codes).

\subsection{Results of CMT Coding}

During the coding process, we identified 36 embodied schemata on which participants grounded their reasoning when describing their tasks and work practices. They correspond to 8 categories of embodied schemata. In Table 1, we report the number of times in which each code was applied through all interviews. We want to remind the reader that we coded the transcript by idea units [2] we were not looking for specific keywords, but rather for full sentences that explained the same concepts. We used the definitions provided in the SIL glossary website. In Appendix A, we report one example of idea unit per schema (from the participants' remarks during the interviews).

\section{PROBLEM STATEMENT, I.E. HOW CMT-CODED DATA CAN BE ANALYZED TO IDENTIFY COMMONALITIES AND DIVERGENCES AT A SPECIFIC MIXED-ABILITY SITE}

Next, the five researchers performed both qualitative and quantitative analyses of the coded transcript data to answer questions aimed at identifying commonalities and divergences in the way in which mixed-ability workers at the digitization lab described their tasks and work practices.

\subsection{Research Questions}

Specifically, during the analysis of the interview transcripts, we focused on three research questions.

- R.Q.1: Do neurodiverse workers and their neurotypical team leader use the same schemata to describe their work tasks? If not, what are the most significant differences?

Significance. We suspected that the neurotypical team leader and the neurodiverse workers might approach similar work tasks and practices from different perspectives. The use of different combinations of mental patterns (embodied schemata) to describe what they do would provide evidence of this diversity of viewpoints.

- R.Q.2: What are the schemata/groups of schemata that workers rely the most upon? Significance. If we are able to identify the schemata or groups of schemata that groups of mixed-ability workers use the most, we can rely on approaches from tangible and embodied interaction literature (e.g., [31], [53]) to craft embodied technologies that better fit their mental patterns.

- R.Q.3: Is there any correlation across different schemata?

Significance. This last question attempts to unveil the network of mental connections [47] that each schema may activate in the brain of mixed-ability workers.

\subsection{Statistical Analysis}

After coding the transcripts, we prepared the data for the statistical analysis, in order to investigate the quantitative aspects of our research questions.

In order to answer R.Q.1, i.e., to investigate the differences between the neurotypical team leader and the other workers, we constructed two 3-columns tables, one for the individual schemata, and 
Table 1. Embodied Schemata that we coded in the transcripts of the interviews

\begin{tabular}{|c|c|c|}
\hline Category & Schema & Instances \\
\hline \multirow[t]{10}{*}{ FORCE } & RESISTANCE & 27 \\
\hline & BLOCKAGE & 37 \\
\hline & REMOVAL OF RESTRAINT & 22 \\
\hline & COMPULSION & 6 \\
\hline & ENABLEMENT & 30 \\
\hline & COUNTERFORCE & 7 \\
\hline & BALANCE & 13 \\
\hline & MOMENTUM & 5 \\
\hline & DIVERSION & 7 \\
\hline & ATTRACTION & 19 \\
\hline \multirow[t]{7}{*}{ SPACE } & UP-DOWN & 4 \\
\hline & STRAIGHT & 13 \\
\hline & CONTACT & 7 \\
\hline & LEFT-RIGHT & 12 \\
\hline & VERTICALITY & 5 \\
\hline & CENTER & 1 \\
\hline & NEAR-FAR & 3 \\
\hline \multirow[t]{3}{*}{ ATTRIBUTE } & BEFORE-DURING-AFTER & 4 \\
\hline & STRONG-WEAK & 2 \\
\hline & WARM-COLD & 4 \\
\hline \multirow[t]{3}{*}{ CONTAINMENT } & CONTAINER & 5 \\
\hline & CONTENT & 5 \\
\hline & IN-OUT & 4 \\
\hline \multirow[t]{4}{*}{ MULTIPLICITY } & MERGING & 9 \\
\hline & PART-WHOLE & 9 \\
\hline & COLLECTION & 9 \\
\hline & SPLITTING & 4 \\
\hline \multirow[t]{3}{*}{ IDENTITY-SURFACE } & SUPERIMPOSITION & 4 \\
\hline & MATCHING & 14 \\
\hline & IDENTITY-FACE & 14 \\
\hline LOCOMOTION & SOURCE-PATH-GOAL & 3 \\
\hline SCALE & MORE-LESS & 37 \\
\hline \multirow[t]{2}{*}{ PROCESS } & CYCLE & 25 \\
\hline & ITERATION & 2 \\
\hline
\end{tabular}

another for the categories of schemata. In each table, we included the participant id, each schema or category that we coded, and the frequency (i.e., the number of times we coded that schema/category in that participant's transcript). We then used the model selection function of SPSS to identify a loglinear model that fits the data and that we could then use to perform a 2-way loglinear analysis to identify the statistically significant differences in the frequency of use of each schema/category across participants. We want to highlight that we did not use a (simpler) chi-square test because the number of groups would have required many z-test comparisons during the posthoc analysis, and because many idea units were coded with multiple (not only one) schemata -chi square is not good for multiple-choice problems. 
For R.Q.2, i.e. to identify the schemata/category that each participant used the most, we followed a similar approach. Specifically, we used the same table that we created for R.Q.1 and we performed the same loglinear analysis, but we focused on the statistically significant differences in the frequency of use of schemata by each participant.

Finally, to address R.Q.3, we constructed a different table in which we listed each participant in the first column, and we then reported the frequency of use of each schema for that participant in different columns. We performed a correlation analysis using Pearson's product-moment correlation to assess the relationships across the use of different schemata (i.e., whether an increase/decrease in the use of a schema was correlated with an increase/decrease in the use of a different schema).

\subsection{Venn Diagrams}

Next, we explored how certain schemata were used by different participants. For example, our most frequently used code was BLOCKAGE. We created an Excel sheet with the five interviewees as separate columns and wrote quotes from the interview that were coded as instances of BLOCKAGE. Through this activity, we explored how a certain schema was used to express different themes by different workers; we also identified few common themes across different participants. We reported these themes into Venn Diagrams in order to visualize differences and common themes.

\section{RESULTS FROM THE MIXED-ABILITY LIBRARY SITE}

\subsection{R.Q.1: Do neurodiverse workers and the neurotypical team leader use the same schemata to describe their work tasks? If not, what are the most significant differences?}

7.1.1 Common Themes. We started the analysis by focusing on three of the most used schemata: BLOCKAGE, ENABLEMENT, and REMOVAL OF RESTRAINT. We selected these three schemata because they are particularly meaningful to understand the challenges that people encounter during their work tasks (BLOCKAGE), the technologies/tools that facilitate their work (REMOVAL OF RESTRAINT), and what enables them to personally carry out their daily responsibilities (ENABLEMENT). In Figure 3, we report the themes that we identified for the five people that we interviewed (team leader and the other workers). We were particularly interested in the themes that were mentioned by multiple participants, which are listed in the intersection of the Venn diagrams in Figure 3. Full-size versions of the three diagrams in Figure 3 are in Appendix B (the text is particularly small here).

For example, in the case of BLOCKAGE, both the team leader and P3 reported that assigning or receiving books that are too difficult to scan (for example, because they are very long, or because some pages have deteriorated) can be a challenging tasks that causes some workers to freeze: [Team Leader, when describing books]: "It is okay to raise the bar, but it is not good that this has to cause stress"

[P3]: "Let's say when they give me difficult books, that is."

\subsubsection{Differences by Schemata. In general, the Venn diagrams in Figure 3 show (qualitatively) a} limited overlapping between the team leader and the other workers. We used a loglinear analysis to dig more on what may cause these different perspectives and, in particular, to identify the schemata that the team leader used in different frequencies when compared with the other workers.

First, we needed to determine if there was a significant interaction between the participant (team leader and all other workers) and the frequency of use of the embodied schemata at all. The likelihood ratio for the two-way partial association between Participant (team leader and all other workers) and Schemata was statistically significant, $\chi^{2}(140)=192.57, p=0.002$. In other 


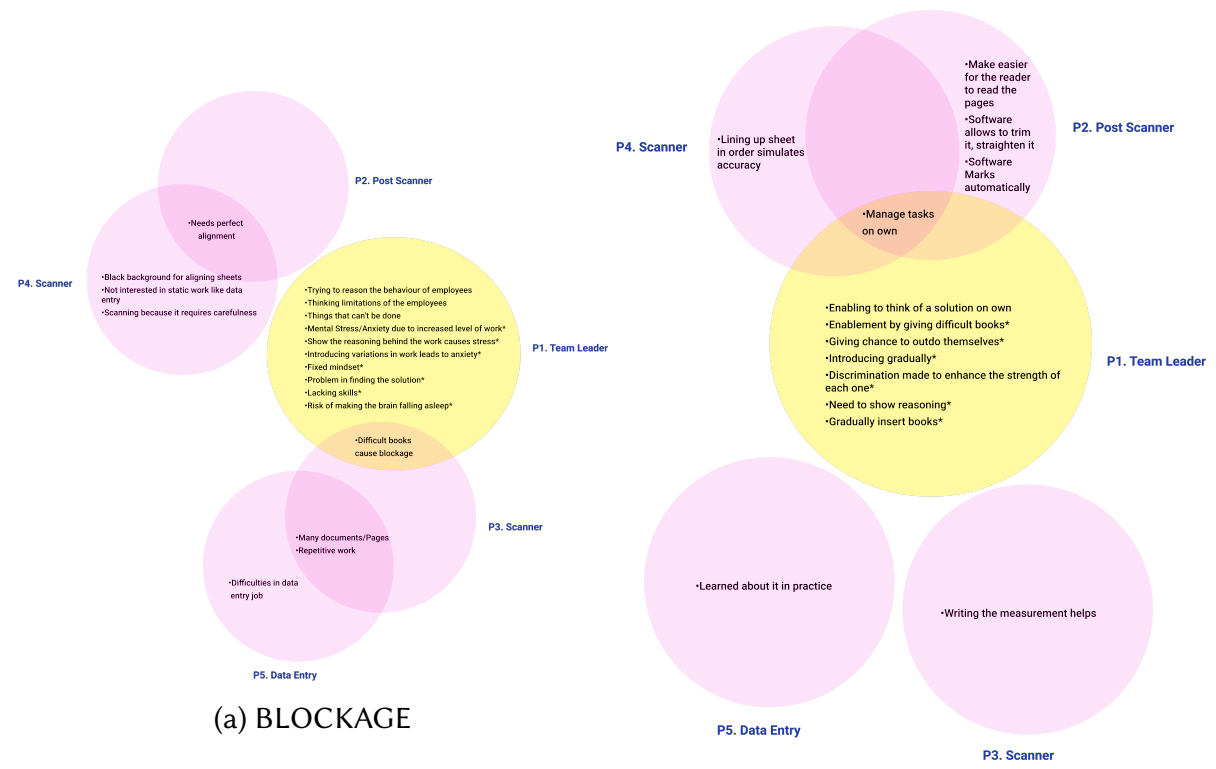

(b) ENABLEMENT

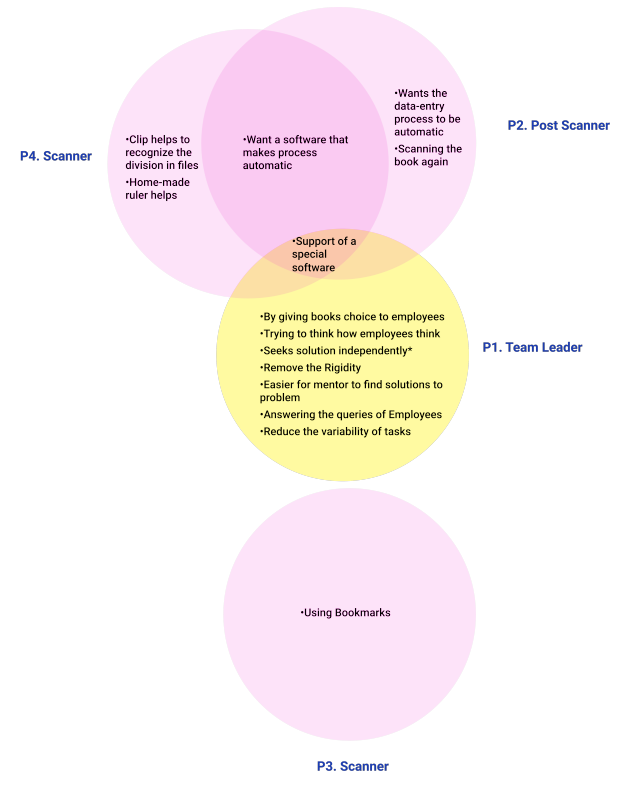

(c) REMOVAL OF RESTRAINT

Fig. 3. Venn diagrams listing the disjoint and the (few) overlapping themes that we identified when looking at participants' remarks that were coded as BLOCKAGE, ENABLEMENT, or REMOVAL OF RESTRAINT. Star $\left.{ }^{*}\right)$ denotes themes that the Team Leader discussed about the work of other people, rather than her own.

words, different participants used embodied schemata in different frequencies during the interviews, i.e., their reasoning was grounded on different combinations of schemata. The two main effects, Participant and Schemata, were also statistically significant. 
Table 2. Schemata for which we detected a statistically significant difference in the frequency of use by the team leader vs. the other workers

\begin{tabular}{|c|c|c|c|c|c|c|}
\hline Category & Schema & Participant & Estimate $(\lambda)$ & $Z$ & $p$ & $\%$ of baseline \\
\hline \multirow[t]{15}{*}{ Force } & \multirow[t]{5}{*}{ Blockage } & Team Leader & 3.199 & 15.833 & & (baseline) \\
\hline & & P2 & -3.892 & -2.724 & 0.006 & $2 \%$ \\
\hline & & P3 & -1.946 & -3.405 & 0.001 & $14 \%$ \\
\hline & & P4 & -1.695 & -3.304 & 0.001 & $18 \%$ \\
\hline & & P5 & -1.327 & -3.00 & 0.003 & $27 \%$ \\
\hline & \multirow[t]{2}{*}{ Resistance } & Team Leader & 2.251 & 6.939 & & (baseline) \\
\hline & & P3 & -1.335 & -2.101 & 0.036 & $26 \%$ \\
\hline & \multirow[t]{4}{*}{ Removal of Restraint } & Team Leader & 2.442 & 8.282 & & (baseline) \\
\hline & & P2 & -1.190 & -1.949 & 0.050 & $30 \%$ \\
\hline & & P3 & -2.037 & -2.346 & 0.019 & $13 \%$ \\
\hline & & P5 & -3.135 & -2.170 & 0.030 & $4 \%$ \\
\hline & \multirow[t]{4}{*}{ Enablement } & Team Leader & 2.741 & 10.791 & & (baseline) \\
\hline & & $\mathrm{P} 2$ & -1.036 & -2.088 & 0.037 & $35 \%$ \\
\hline & & P3 & -1.825 & -2.677 & 0.007 & $16 \%$ \\
\hline & & P5 & -1.825 & -2.677 & 0.007 & $16 \%$ \\
\hline \multirow[t]{4}{*}{ Scale } & \multirow[t]{4}{*}{ More/Less } & Team Leader & 2.803 & 11.387 & & (baseline) \\
\hline & & $\mathrm{P} 2$ & -1.099 & -2.231 & 0.026 & $33 \%$ \\
\hline & & P3 & -1.887 & -2.781 & 0.005 & $15 \%$ \\
\hline & & P5 & -1.551 & -2.635 & 0.008 & $21 \%$ \\
\hline \multirow[t]{5}{*}{ Identity } & \multirow[t]{5}{*}{ Matching } & Team Leader & 2.526 & 8.930 & & (baseline) \\
\hline & & P2 & -2.120 & -2.454 & 0.014 & $12 \%$ \\
\hline & & P3 & -2.120 & -2.454 & 0.014 & $12 \%$ \\
\hline & & P4 & -3.219 & -2.232 & 0.026 & $4 \%$ \\
\hline & & P5 & -3.219 & -2.232 & 0.026 & $4 \%$ \\
\hline
\end{tabular}

Next, we focused on the schemata that the neurotypical team leader used in different frequencies when compared to the neurodiverse workers. The parameter estimates $\lambda$ for the loglinear model are reported in Table 2 . The reader should notice that $\lambda$ represents the log of the odds ratio when compared to a baseline; as a consequence, the odds ratio (as a percent of the baseline) can be computed as $e^{\lambda}$. We repeated the estimate using the team leader and each of the 36 schemata that we detected (in the loglinear function of SPSS) as baseline. Table 2 only reports the results that are statistically significant $(\mathrm{p}<0.05)$-thus, this table only lists 6 schemata. For example, when looking at BLOCKAGE, the estimate $\lambda=-3.892$ for P2 means that P2 made statements that we coded as instances of BLOCKAGE only $e^{-3.892}=2 \%$ of the times that the team leader made remarks based on that schema, i.e. P2 used BLOCKAGE fifty times less frequently than the team leader.

7.1.3 Differences by Category of Schemata. Similarly, the likelihood ratio for the two-way partial association between Participant and Category of Embodied Schemata was statistically significant, $\chi^{2}(28)=46.721, p=0.015$. In other words, different participants used different frequencies of categories of schemata when describing their work. As we discussed, we focused the analysis on the differences between the team leader and the other workers. Table 3 reports the four categories of schemata (Force, Space, Identity, and Process) that the team leader used in a statistically significantly different way than the other workers. 
Table 3. Categories of Schemata for which we detected a statistically significant difference in the frequency of use by the team leader vs. the other workers

\begin{tabular}{|l|l|c|c|c|c|}
\hline Category & Participant & Estimate $(\lambda)$ & $Z$ & $p$ & \% of baseline \\
\hline Force & Team Leader & 4.483 & 42.174 & & (baseline) \\
& P2 & -1.513 & -6.046 & 0.0005 & $22 \%$ \\
& P3 & -2.235 & -6.537 & 0.0005 & $11 \%$ \\
& P4 & -0.913 & -4.598 & 0.0005 & $40 \%$ \\
& P5 & -1.369 & -5.800 & 0.0005 & $25 \%$ \\
\hline Space & Team Leader & 2.918 & 12.550 & & (baseline) \\
& P3 & -1.665 & -2.856 & 0.004 & $19 \%$ \\
& P5 & -2.512 & -2.959 & 0.003 & $8 \%$ \\
\hline Identity & Team Leader & 2.741 & 10.791 & & (baseline) \\
& P2 & -1.237 & -2.310 & 0.021 & $29 \%$ \\
& P3 & -1.825 & -2.677 & 0.007 & $16 \%$ \\
& P4 & -1.036 & -2.088 & 0.037 & $35 \%$ \\
\hline Process & Team Leader & 2.803 & 11.387 & & (baseline) \\
& P2 & -0.932 & -2.012 & 0.440 & $39 \%$ \\
& P3 & -1.887 & -2.781 & 0.005 & $15 \%$ \\
& P5 & -1.551 & -2.635 & 0.008 & $21 \%$ \\
\hline
\end{tabular}

We want to highlight that the categories of schemata provide a higher level of granularity than the individual embodied schemata: some results here are somehow expected (the differences on the Force category could have been anticipated given the difference on four Force schemata -BLOCKAGE, RESISTANCE, REMOVAL OF RESTRAINT, and ENABLEMENT); others differences (Space and Process) were not captured in the previous level of analysis.

\subsection{R.Q.2: What are the schemata/groups of schemata that mixed-ability workers rely the most upon?}

After looking at the differences in thinking patterns (schemata and categories) between the neurotypical team leader and the other workers, we conducted a similar analysis at the participant level, in order to identify the embodied schemata and the categories of embodied schemata that each worker relied the most upon.

7.2.1 Most Used Schemata. To conduct this portion of the analysis, we used the same loglinear model that we adopted to answer R.Q.2. We did not, however, set the team leader as baseline. Rather, for each worker: (1) we first identified the embodied schema $E S_{1}$ that was used the most by that worker; (2) we set that worker and her/his most used schema as baseline; and, (3) we identified the schemata that were used statistically significantly less than $E S_{1}$ by that participant. If other schemata were not used significantly less than $E S_{1}$, we repeated the analysis with those schemata as baselines. This allowed us to identify the schema/schemata that was/were used the most by each participant.

The supervisor heavily relied on the BLOCKAGE schema, which represents $14 \%$ of the total number of schemata that we coded in her transcript. She used BLOCKAGE significantly more than all other schemata $(\mathrm{p}<0.05)$, except for ENABLEMENT $(\mathrm{p}=0.158)$ and MORE/LESS $(\mathrm{p}=0.214)$. ENABLEMENT covered $8.7 \%$ of the transcript and was used significantly more than most other schemata $(p<0.032)$, except for BLOCKAGE $(p=0.158)$, COMPULSION $(p=0.063)$, CYCLE $(p=0.235)$, 
Table 4. Detail on the Force category: $X$ denotes that Force schemata were used statistically significantly more than those in the other listed category (e.g., Space, Attribute, etc.) by that participant.

\begin{tabular}{|l|c|c|c|c|c|c|c|}
\hline Participant & Space & Attribute & Containment & Multiplicity & Identity & Scale & Process \\
\hline Team Leader & $\mathrm{X}$ & $\mathrm{X}$ & $\mathrm{X}$ & $\mathrm{X}$ & $\mathrm{X}$ & $\mathrm{X}$ & $\mathrm{X}$ \\
\hline P2 & & $\mathrm{X}$ & $\mathrm{X}$ & $\mathrm{X}$ & $\mathrm{X}$ & $\mathrm{X}$ & $\mathrm{X}$ \\
\hline P3 & & & $\mathrm{X}$ & & & & \\
\hline P4 & $\mathrm{X}$ & $\mathrm{X}$ & $\mathrm{X}$ & $\mathrm{X}$ & $\mathrm{X}$ & $\mathrm{X}$ & $\mathrm{X}$ \\
\hline P5 & $\mathrm{X}$ & $\mathrm{X}$ & $\mathrm{X}$ & $\mathrm{X}$ & $\mathrm{X}$ & $\mathrm{X}$ & $\mathrm{X}$ \\
\hline
\end{tabular}

MATCHING ( $p=0.571)$, MORE/LESS ( $p=0.860)$, REMOVAL OF RESTRAINT $(p=0.235)$, and RESISTANCE ( $p=0.235$ ). Finally, MORE/LESS represents $9.3 \%$ of the transcript and was used more than most other schemata $(\mathrm{p}<0.044)$, except for BLOCKAGE $(\mathrm{p}=0.214)$ and ENABLEMENT $(\mathrm{p}=0.860)$, CYCLE $(\mathrm{p}=0.175)$, MATCHING ( $\mathrm{p}=0.459)$, REMOVAL OF RESTRAINT $(\mathrm{p}=0.347)$, and RESISTANCE $(\mathrm{p}=0.175)$.

P2 seemed to privilege CYCLE, ENABLEMENT, and MORE/LESS, which represent $8.2 \%$ of the codes for that participant, P3 used CONTENT and CYCLE in $11.1 \%$ of the transcript, and P5 relied on ATTRACTION and BLOCKAGE in $15.6 \%$ and $11.1 \%$ of his remarks, respectively. We do not have enough data, however, to determine if those schemata were used statistically significantly more than others. Finally, P4 used MORE/LESS in $13.6 \%$ of the transcript, significantly more than most other schemata $(p<0.05)$, except for CYCLE ( $p=0.092)$, ENABLEMENT $(p=0.245)$, IDENTITYFACE $(p=0.092)$, LEFT-RIGHT ( $p=0.155)$, REMOVAL OF RESTRAINT and RESISTANCE $(p=0.362)$, STRAIGHT $(\mathrm{p}=0.155)$.

In general, these results suggest that the neurotypical team leader tended to rely on a more focused set of schemata when describing the team's work, while the other workers used a more widespread mix of schemata.

7.2.2 Most Used Category of Schemata. The analysis by categories of schemata reveals that, despite their differences, all workers privileged Force schemata when describing their team's work and their tasks. Specifically:

- the team leader used Force schemata in $53 \%$ of the transcript. She used the force category significantly more than any other category $(\mathrm{p}<=0.0005)$;

- P2 relied on Force schemata in $32.2 \%$ of the interview. He used the Force category significantly more than all others $(\mathrm{p}<=0.05)$ except for the Space category $(\mathrm{p}=0.15)$. In particular, P2 used Space in $25.4 \%$ of the transcript, which is significantly more than most other categories $(\mathrm{p}<=0.021)$ except Force, Identity and Scale $(\mathrm{p}=0.063)$;

- P3 used Force schemata in $33.3 \%$ of the transcript, which in his case only means that he used the Force category significantly more than the Multiplicity category $(\mathrm{p}=0.036)$;

- P4 and P5 used Force schemata in $45.5 \%$ and $50 \%$ of the interview, respectively; the Force category was used significantly more than all others ( $\mathrm{p}<=0.001$ for $\mathrm{P} 4, \mathrm{p}<=0.009$ for $\mathrm{P} 5$ ).

The results for the Force category are illustrated in Table 4

\subsection{R.Q.3: Is there a correlation across different schemata?}

We conducted a Pearson's correlation analysis on the number of schemata that we coded for the neurodiverse workers -excluding the neurotypical team leader. We excluded the neurotypical team leader because we know from the results of R.Q.1 that there were significant differences in her use of schemata. 
Table 5. Strong Pearson's correlations $(r>0.9)$ that we detected across embodied schemata, when considering the four mixed-ability workers (and not the neurotypical team leader). In parenthesis, we report the correlation coefficient. All correlations in this table are significant at the $p=0.05$ level (2-tailed)

\begin{tabular}{|l|l|}
\hline ATTRACTION & SUPERIMPOSITION (0.973) \\
\hline BALANCE & $\begin{array}{l}\text { REMOVAL OF RESTRAINT (0.959), STRAIGHT } \\
(0.990)\end{array}$ \\
\hline BEFORE/DURING/AFTER & CENTER (1.000), MOMENTUM (1.000) \\
\hline BLOCKAGE & MATCHING (-0.980), SPLITTING (0.980) \\
\hline CENTER & MOMENTUM (-1.000) \\
\hline COLLECTION & CYCLE (0.973) \\
\hline CONTACT & CONTAINER $(0.973)$ \\
\hline CONTENT & RESISTANCE (-0.980) \\
\hline COUNTERFORCE & MORE/LESS (0.951) \\
\hline ENABLEMENT & $\begin{array}{l}\text { IN/OUT (-0.980), LEFT/RIGHT (0.999), MOMEN- } \\
\text { TUM (0.980), STRAIGHT (0.966) }\end{array}$ \\
\hline IDENTITY & $\begin{array}{l}\text { MATCHING (-0.962), RESISTANCE (0.966), SPLIT- } \\
\text { TING (0.962) }\end{array}$ \\
\hline LEFT/RIGHT & $\begin{array}{l}\text { ENABLEMENT (0.999), IN/OUT (-0.988), MERG- } \\
\text { ING (0.988), STRAIGHT (0.957) }\end{array}$ \\
\hline NEAR/FAR & WARM/COLD (1.000) \\
\hline REMOVAL OF RESTRAINT & BALANCE (0.959), STRAIGHT (0.983) \\
\hline RESISTANCE & $\begin{array}{l}\text { CONTENT (-0.980), IDENTITY (0.966), } \\
\text { PART/WHOLE (0.976) }\end{array}$ \\
\hline STRAIGHT & $\begin{array}{l}\text { BALANCE (0.990), ENABLEMENT (0.966), } \\
\text { LEFT/RIGHT (0.957), REMOVAL OF RESTRAINT } \\
(0.983)\end{array}$ \\
\hline UP/DOWN & SCALE (1.000), VERTICALITY (1.000) \\
\hline
\end{tabular}

The Pearson's correlation analysis revealed 28 statistically significant (at a $\mathrm{p}<0.05$ level, 2 tailed) strong correlations across the embodied schemata used by neurodiverse workers. For example, we detected a strong positive correlation between BALANCE and STRAIGHT $(p=0.990)$, with BALANCE "explaining" (statistically, not casually) 98\% of the variation in the instances of STRAIGHT. With "explaining" we refer to the coefficient of determination, which is computed as the square of the correlation coefficient $\left(p^{2}\right)$. In other words, participants that used BALANCE more frequently also used STRAIGHT more frequently, and vice-versa. We detected, instead, a negative correlation between CONTENT and RESISTANCE; in other words, people who referred more to work tasks in terms of CONTENT also discussed/reported less instances of RESISTANCE.

These correlations, along with their correlation coefficients, are listed in Table 5.

We cannot provide a similar correlation analysis for the neurotypical team leader, because we would only have one entry in that group (e.g., we cannot assess if a higher or lower number of statements based on STRAIGHT cause an increase on statements based on BALANCE, because those two numbers are constant if we only include one participant in the analysis).

We want to highlight, however, that the results of this correlation analysis are by no means universal: rather, they refer to a specific community of workers. For example, if we include the neurotypical team leader in the correlation analysis, along with the other mixed-ability workers, we obtain different results. In particular, the Pearson's correlation analysis only reveals 10 statistically 
Table 6. Strong Pearson's correlations $(r>0.9)$ that we detected across embodied schemata, when we included the neurotypical team leader in the analysis. All correlations in this table are significant at the $p=0.01$ level (2-tailed)

\begin{tabular}{|c|c|c|c|c|c|}
\hline & BLOCKAGE & RESISTANCE & REM. REST. & ENABLEMENT & STRAIGHT \\
\hline COMPULSION & 0.982 & & & & \\
MATCHING & -0.959 & & & & \\
\hline PART-WHOLE & & 0.968 & & & \\
\hline BALANCE & & & 0.970 & 0.988 & \\
COUNTERFORCE & & & 0.963 & 0.962 & \\
ENABLEMENT & & & 0.988 & & \\
MERGING & & & 0.951 & & 0.932 \\
\hline LEFT-RIGHT & & & & & \\
\hline
\end{tabular}

significant strong correlations across embodied schemata. The values of these correlation coefficients are reported in Table 6 -although they are not particularly relevant for our methodological approach, we included them to show that they differ from those in Table 5.

\section{DISCUSSION, I.E. HOW TO USE THE RESULTS TO INFORM THE DESIGN OF TECHNOLOGIES IN SUPPORT OF MIXED ABILITY WORKPLACES}

\subsection{Collecting and Analyzing Data Using CMT in Mixed-Ability Workplaces}

Through the case study of the digitization lab, we outlined an approach on how to collect data in mixed-ability workplaces and analyze them with the lenses of Conceptual Metaphor Theory. We cannot rely on short contextual inquiry sessions or semi-structured interviews (as successfully used in very different settings by Hurtienne [33]). As we highlighted in Section 4, the presence of people with cognitive disabilities requires researchers and practitioners to carefully plan preliminary activities aimed at developing trust [35] and equal relationships [12] between researchers and participants. From our experience, creating an introductory video, and situating ourselves in the mixed-ability work environment for a full week were two effective techniques to achieve these goals. Additionally, coding transcripts with the lenses of CMT allowed us to identify commonalities and divergences among diverse groups of workers, but it required us to code transcripts by idea units and to craft a rigorous process to discuss and resolve disagreement among coders (as we describe in Section 5).

\subsection{Using Convergent and Divergent CMT-Coded Data to Design Technologies in Support of Mixed-Ability Work}

In Sections 7.1 and 7.2, we illustrated how CMT-coded data might be used to explore the dynamics of mixed-ability workplaces and to identity commonalities and differences in thinking across different groups of workers. These commonalities and differences are especially important to be aware of when designing for mixed-ability workplaces, since neurotypical and neurodiverse employees may be using and interpreting metaphors differently [9, 38, 40, 41]. We believe that identifying convergent and divergent schemata and groups of schemata provides a variety of insights on how to support mixed-ability work.

8.2.1 Convergent Schemata: Designing Intuitive Technologies/Interfaces Within Communities of Workers. Relying on convergent schemata may enable designers to craft "intuitive" interfaces, because embodied schemata are preconceptual mental structures: the metaphoric associations 
happen extremely quickly in our brains, without our conscious realization that we are using a specific schema to decide what to do [48].

For example, the results of R.Q.2 show that both P2 and P3 frequently used CYCLE when describing their job tasks. Although the focus of R.Q.2 was at the individual level, this suggests that incorporating a data visualization based on cycle diagrams or cycle plots [42] in their scanner/data processing interface may help P2 and P3 with keeping track of their daily progress.

This approach, however, does not easily allow to create bridges across different groups of workers (in our case, the two teams of neurodiverse workers, and their neurotypical leaders): the results of R.Q.1 indicate significant differences in their use of embodied schemata. In other words, when designing for mixed-ability workplaces, we cannot assume that embodied schemata can always be mapped to functionalities and interfaces that are intuitive for all. Rather, we may need to focus on one community of workers at a time.

8.2.2 Divergent Schemata: Making Differences Visible Across Communities of Workers. Divergent schemata, on the other hand, can provide insights on where points of connections across different communities are particularly needed. In this context, we could envision crafting technologies that make these divergent patterns visible to coworkers.

For example, from the analysis for R.Q.1, we discovered that MORE/LESS was used significantly differently by mixed-ability workers and their team leader. So, we could consider revamping the button-based scanner interface in a way that is more directly based on the MORE/LESS schema, for instance by letting workers adjust the brightness by adding more (or less) paper clips into a coffee mug (equipped with a pressure sensor). This change could surface the different metaphorical associations that each worker uses and make them more explicit, allowing employees to build an understanding of their different viewpoints.

Although there is not a recipe on how to transform embodied schemata in design patterns, we believe that highlighting divergent use of schemata can a the starting point -for researchers and practitioners -to design more "inclusive" interfaces in support of mixed-ability sites. We want to highlight, however, that these patterns are most likely site-dependent, so they need to be identified through the process that we highlight in this paper. Future studies should explore whether there are common patterns across neurodiverse workers at different sites.

\subsection{The Multiple Roles of the Correlations Across Schemata}

The correlation analysis (R.Q.3) that we report on in Section 7.3 allows to more into the connection of mental patterns [47] used by a specific groups of workers (in our case, the four neurodiverse workers). In particular, the results of the correlation analysis provide provide at least two different types of insights to designers and practitioners.

8.3.1 Leveraging on Mental Connections to Design Intuitive Interfaces. First, some strong correlations -like the one between UP/DOWN and SCALE - may provide additional insights for the design of "intuitive" user interfaces within a community of workers. This may be particularly valuable for correlations across SPACE and ATTRIBUTE schemata, because we can rely on prior HCI literature that has focuses on these two categories for the design of intuitive installations (e.g., [53]). For example, the relationship between SCALE and UP/DOWN suggests a metaphorical projection [36] between these two schemata; thus, we could think of designing an interface in which moving the cursor up and down on the screen (or a physical object on the desk) increases or decreases the scale of a document.

8.3.2 Highlighting Challenges and Opportunities in Work Practices. Second, other strong correlations -in particular those stemming from BLOCKAGE, REMOVAL OF RESTRAINT, RESISTANCE, and 
ENABLEMENT, may provide a way to dig on recurrent challenges and opportunities in the work processes, tasks, and practices at a specific mixed-ability site. For example, the correlation between ENABLEMENT and STRAIGHT points to a practice that neurodiverse workers discussed with researchers, i.e. that using a square ruler enabled them to keep books straight while scanning them.

\subsection{Using CMT-Based Venn Diagrams to Identify Challenges and Opportunities}

On a similar note, using the idea units that we coded as BLOCKAGE, ENABLEMENT, and REMOVAL of RESTRAINT to group themes and compile Venn Diagrams allowed us to identify challenges and opportunities provided by specific tasks, work practices, and technologies.

8.4.1 BLOCKAGE: Recognize Challenging Tasks. Workers' statements grounded on BLOCKAGE allow to identify challenging tasks. For example, both P2 and P4 identified the need for a perfect alignment of books as an example of something that can block their work; surprisingly, this view was not shared by the neurotypical team leader, who instead attributed their struggles in deciding when a book was aligned well enough to a lack of skills. Identifying and discussing these critical challenges with the mixed-ability workers may be enough to improve collaboration practices across different communities of workers, and enable the team leader to better support the work of neurodiverse workers.

8.4.2 ENABLEMENT: Identify Helpful Work Practices. Comments founded on ENABLEMENT highlight work practices that are perceived as particularly helpful by mixed-ability workers. For example, P2, P4, and the team leader discussed how managing tasks on your own is crucial for the work at the digitization lab. Thus, researchers and practitioners may want to focus on designing technologies that fully support these helpful work practices.

8.4.3 REMOVAL OF RESTRAINT: Point to Useful Technologies. Finally, remarks based on REMOVAL OF RESTRAINT point to existing technologies or tools that facilitate tasks and work practices. For instance, all mixed-ability workers (except for P3) identified a specific software as a tool that improves their productivity. This could mean, for example, that new workers joining the project should be promptly introduced to that software. Also, this could highlight technologies and interfaces that need to be constantly kept updated, because they are perceived as essential by mixed-ability workers.

\section{BROAD IMPLICATIONS FOR THE DESIGN AND STUDY OF TECHNOLOGIES FOR MIXED-ABILITY WORKPLACES}

\subsection{Implications for the Design of Technologies: Towards Tangible and Embodied Interaction for Mixed-Ability Workplaces}

The results of R.Q.1 indicate that the majority of schemata that workers used belong to the FORCE category. This finding highlights a clear distinction between the use of CMT in work environments and previous work on designing technologies with embodied schemata: for example, Antle et. al [4] suggests focusing on Space-related schemata in informal learning settings, while Macaranas et al. [53] analyzes how Space and Attribute schemata can be used in the design of tangible interfaces.

The prominence of Force-based schemata in mixed-ability workplaces opens up opportunities for re-designing the technologies that people use for their daily work. In particular, work interfaces may incorporating ideas from the literature on tangible [34] and embodied [22] [28] interaction. For example, Force schemata could be triggered by haptic feedback, e.g. [51]. Additionally, there is an implicit connection between Full-Body Interaction [14] and Force schemata, because performing hand gestures and body movements requires some degrees of exertion [52] [11]. The work in Springboard [3] can be particularly inspiring in this context: it describes an interactive installation in

Proc. ACM Hum.-Comput. Interact., Vol. 5, No. CSCW2, Article 384. Publication date: October 2021. 
which a screen shows different visualizations depending on how the user is able to BALANCE herself while standing on a platform made from crib mattress springs. Arnold et al. designed persuasive experiences based on a coffee mug for making parents of hospitalized children take time for themselves [71]. Taciana et al. showed that tangible technologies, which combine physicality with interactivity, are possibly beneficial to children with learning disabilities [24]. Similarly, TraInAb is an interactive, collaborative game designed to stimulate people with intellectual disabilities by encouraging cognitive abilities such as memory, calculation and attention. In this the user can interact with the system through everyday objects such as cards, toys, and coins [20].

A possible follow up to this work could involve creating design probes [73] based on the schemata that we want to activate, and using them for conducting collaborative design sessions (with neurodiverse and neurotypical workers) to re-design the interface of the tools that people use the most in their work.

\subsection{Implications for the Study of Technologies: Challenging Ability-Based Workplace Hierarchies}

Ability-based hierarchies are societal structures which favor the work or contributions of nondisabled, neurotypical people over their disabled counterparts [7]. We saw these hierarchies replicated in the organizational hierarchies of the library, where the work of mixed-ability team was coordinated by either an on-site supervisor or neurotypical team leader. Typically, supervisor or team leaders needed to be present in the room as we conducted our design work, and at one point the team leader intervened in one of our interviews with an employee with a contradictory opinion.

Aspects of this dynamic were exposed by our analysis of the interview transcripts, with significant differences between the schemata found in the team leader's language and the other staff's language when describing the same tasks. There were few commonalities between the BLOCKAGES identified by the team leader and those identified by the workers, and the team leader frequently spoke about her responsibility to ENABLE the workers to solve problems that arose in their duties. Moreover, the team leader was significantly more likely to differentiate herself from the other team members through the use of the Identity schemata. This type of analysis of the differences in how the schemata are used may allow researcher to identify critical relational barriers which impact our understanding of workplace dynamics.

\section{LIMITATIONS}

We want to acknowledge that our findings might be dependent on the specific work environment (the university library) and working tasks (document digitization and processing) that we observed. This might also lead to the question of whether it was the varying roles of the participants or the cognitive ability that impacted the data collected. Future research can be conducted to address the limitation, where we could explore the advantages and disadvantages of each role and how it impacts the participants' cognition to create a more thorough discussion.

One limitation of this work is that the team leader was neurotypical, and the other employees were neurodiverse. This makes it difficult to disentangle whether differences in metaphor use were related to workplace role, or neurodiversity. Unfortunately, workplace role and neurodiversity are highly related - people with disabilities are typically stuck in entry-level positions [50] and have trouble moving up in the organization due to ableist hierarchies $[18,46]$. Future work should intentionally seek out settings with neurotypical and neurodiverse employees in equal roles, or with neurodiverse team leaders.

As mentioned in Section 9.2, the team leader or supervisors were present during all our activities, and at one point the neurotypical team leader interrupted our questioning to try and clarify a 
neurodiverse participant's point for him. While prior work has shown that it can be useful in mixedability settings to confirm data with more than one informant [27], the presence of the supervisors may have influenced what the participants said or their comfort during the interviews. To address this in the moment, we publicly asked the team leader to let us conduct the interviews without interruption moving forward, in an attempt to demonstrate that we did not value her opinions over the neurodiverse team members. Future work should consider these dynamics carefully, or think about using other interview techniques, like dyadic interviewing, which may better reflect the interdependent nature of the relationship between the team leader and employees [15].

In terms of the methodological approach that we described, although currently it was situated in a library setting, this can be easily adopted to explore other mixed-ability workplaces.

\section{CONCLUSION}

In this paper, we illustrated how Conceptual Metaphor Theory (CMT) can be applied to a new context: Mixed-Ability Workplaces. Through the description of our fieldwork at a mixed-ability digitization lab at an Italian university library, we described how current approaches to collect data for CMT need to be adapted to integrate CSCW's long history of embedded fieldwork and to incorporate techniques to establish trust and equal relationship with neurodiverse participants. Next, we illustrated a procedure to code transcripts by idea units, while preserving the rigor of the analysis. Last, we used three research questions to highlight how CMT-coded data could be analyzed with the purpose of identifying commonalities and divergences among different groups of mixed-ability workers. We closed with a discussion on how the results of this process can inform the design of technologies that support mixed ability, and with a reflection on broad implications of this research for the design and for the study of technologies for mixed-ability workplaces.

The focus of this paper was on the methodology. Future studies should explore the design processes that communities of researchers and practitioners may use to move from the design ideas that we outline in the discussion to semi and fully functional prototypes.

\section{ACKNOWLEDGMENTS}

This material is based upon work supported by the National Science Foundation under Grant No. \#1928549 (FW-HTF-P: Building Research Capacity by Technological Interventions in Support of Mixed-Ability Workplaces). We thank our participants, collaborators, and anonymous reviewers.

\section{REFERENCES}

[1] Barbara M Altman, Donald J Lollar, and Elizabeth K Rasch. 2014. The Experience of Environmental Barriers among Adults with Disabilities: A National Description. Environmental Contexts and Disability 8 (2014), 33.

[2] Richard C Anderson, Ralph E Reynolds, Diane L Schallert, and Ernest T Goetz. 1977. Frameworks for comprehending discourse. American educational research journal 14, 4 (1977), 367-381.

[3] Alissa N Antle, Greg Corness, and Allen Bevans. 2011. Springboard: Designing image schema based embodied interaction for an abstract domain. In Whole body interaction. Springer, 7-18.

[4] Alissa N Antle, Milena Droumeva, and Greg Corness. 2008. Playing with The Sound Maker : Do Embodied Metaphors Help Children Learn? Proceedings of the 7th international conference on Interaction design and children IDC 08 (2008), 178-185. http://portal.acm.org.www.library.gatech.edu:2048/citation.cfm?id=1463689.1463754

[5] Thomas Armstrong. 2010. Neurodiversity: Discovering the extraordinary gifts of autism, ADHD, dyslexia, and other brain differences. ReadHowYouWant.com.

[6] Roger E Beaty and Paul J Silvia. 2013. Metaphorically speaking: Cognitive abilities and the production of figurative language. Memory \& cognition 41, 2 (2013), 255-267.

[7] Cynthia L Bennett, Erin Brady, and Stacy M Branham. 2018. Interdependence as a frame for assistive technology research and design. In Proceedings of the 20th International ACM SIGACCESS Conference on Computers and Accessibility. $161-173$

Proc. ACM Hum.-Comput. Interact., Vol. 5, No. CSCW2, Article 384. Publication date: October 2021. 
[8] Laura Benton, Asimina Vasalou, Rilla Khaled, Hilary Johnson, and Daniel Gooch. 2014. Diversity for design: a framework for involving neurodiverse children in the technology design process. In Proceedings of the SIGCHI conference on human factors in computing systems. 3747-3756.

[9] Simon Bignell and Kate Cain. 2007. Pragmatic aspects of communication and language comprehension in groups of children differentiated by teacher ratings of inattention and hyperactivity. British fournal of Developmental Psychology 25, 4 (2007), 499-512.

[10] Stacy M Branham and Shaun K Kane. 2015. The invisible work of accessibility: how blind employees manage accessibility in mixed-ability workplaces. In Proceedings of the 17th International ACM SIGACCESS Conference on Computers \& Accessibility. ACM, 163-171.

[11] Thisum Buddhika, Haimo Zhang, Samantha W. T. Chan, Vipula Dissanayake, Suranga Nanayakkara, and Roger Zimmermann. 2019. FSense: Unlocking the Dimension of Force for Gestural Interactions Using Smartwatch PPG Sensor. In Proceedings of the 10th Augmented Human International Conference 2019 (Reims, France) (AH2019). Association for Computing Machinery, New York, NY, USA, Article 11, 5 pages. https://doi.org/10.1145/3311823.3311839

[12] Erin Buehler, William Easley, Samantha McDonald, Niara Comrie, and Amy Hurst. 2015. Inclusion and education: 3D printing for integrated classrooms. In Proceedings of the 17th International ACM SIGACCESS Conference on Computers \& Accessibility. 281-290.

[13] Curt Burgess and Christine Chiarello. 1996. Neurocognitive mechanisms underlying metaphor comprehension and other figurative language. Metaphor and symbol 11, 1 (1996), 67-84.

[14] Francesco Cafaro, Alessandro Panella, Leilah Lyons, Jessica Roberts, and Josh Radinsky. 2013. I see you there! Developing identity-preserving embodied interaction for museum exhibits. In Proceedings of the SIGCHI Conference on Human Factors in Computing Systems. 1911-1920.

[15] Kate Caldwell. 2014. Dyadic interviewing: A technique valuing interdependence in interviews with individuals with intellectual disabilities. Qualitative Research 14, 4 (2014), 488-507.

[16] F Xavier Castellanos, Edmund JS Sonuga-Barke, Michael P Milham, and Rosemary Tannock. 2006. Characterizing cognition in ADHD: beyond executive dysfunction. Trends in cognitive sciences 10, 3 (2006), 117-123.

[17] Frederico da Rocha Tomé Filho, Pejman Mirza-Babaei, Bill Kapralos, and Glaudiney Moreira Mendonça Junior. 2019. Let's Play Together: Adaptation Guidelines of Board Games for Players with Visual Impairment. In Proceedings of the 2019 CHI Conference on Human Factors in Computing Systems. ACM, 631.

[18] Maitraye Das, Darren Gergle, and Anne Marie Piper. 2019. " It doesn't win you friends" Understanding Accessibility in Collaborative Writing for People with Vision Impairments. Proceedings of the ACM on Human-Computer Interaction 3 , CSCW (2019), 1-26.

[19] Hendricks Dawn. 2010. Employment and adults with autism spectrum disorders: Challenges and strategies for success. fournal of Vocational Rehabilitation 2 (2010), 125-134. https://doi.org/10.3233/JVR-2010-0502

[20] Elena de la Guía, María Lozano, and Victor R Penichet. 2013. TrainAb: a solution based on tangible and distributed user interfaces to improve cognitive disabilities. In CHI'13 Extended Abstracts on Human Factors in Computing Systems. 3039-3042.

[21] Christine Domzal, Andrew Houtenville, and Ravi Sharma. 2008. Survey of employer perspectives on the employment of people with disabilities: Technical report. Office of Disability Employment Policy, Department of Labor.

[22] Paul Dourish. 2004. Where the action is: the foundations of embodied interaction. MIT press.

[23] Felix R Dreyer, Dietmar Frey, Sophie Arana, Sarah von Saldern, Thomas Picht, Peter Vajkoczy, and Friedemann Pulvermüller. 2015. Is the motor system necessary for processing action and abstract emotion words? Evidence from focal brain lesions. Frontiers in Psychology 6 (2015), 1661.

[24] Taciana Pontual Falcão and Sara Price. 2012. Tangibles for students with intellectual disabilities. In Proceedings of the 11th International Conference on Interaction Design and Children. 371-374.

[25] Dedre Gentner and Donald R Gentner. 2014. Flowing waters or teeming crowds: Mental models of electricity. In Mental models. Psychology Press, 107-138.

[26] Martin Heidegger. 1988. The basic problems of phenomenology. Vol. 478. Indiana University Press.

[27] Andrea Hollomotz. 2018. Successful interviews with people with intellectual disability. Qualitative Research 18,2 (2018), 153-170.

[28] Eva Hornecker. 2011. The role of physicality in tangible and embodied interactions. interactions 18, 2 (2011), 19-23.

[29] Jörn Hurtienne. 2011. Image schemas and design for intuitive use. (2011).

[30] Jörn Hurtienne. 2017. How cognitive linguistics inspires HCI: image schemas and image-schematic metaphors. International fournal of Human-Computer Interaction 33, 1 (2017), 1-20.

[31] Jörn Hurtienne and Johann Habakuk Israel. 2007. Image schemas and their metaphorical extensions: intuitive patterns for tangible interaction. In Proceedings of the 1st international conference on Tangible and embedded interaction. 127-134.

[32] Jörn Hurtienne, Johann Habakuk Israel, and Katharina Weber. 2008. Cooking up real world business applications combining physicality, digitality, and image schemas. In Proceedings of the 2 nd international conference on Tangible and 
embedded interaction. 239-246.

[33] Jörn Hurtienne, Kerstin Klöckner, Sarah Diefenbach, Claudia Nass, and Andreas Maier. 2015. Designing with image schemas: resolving the tension between innovation, inclusion and intuitive use. Interacting with Computers 27, 3 (2015), 235-255.

[34] Hiroshi Ishii and Brygg Ullmer. 1997. Tangible bits: towards seamless interfaces between people, bits and atoms. In Proceedings of the ACM SIGCHI Conference on Human factors in computing systems. 234-241.

[35] Stefan Johansson, Jan Gulliksen, and Ann Lantz. 2015. User participation when users have mental and cognitive disabilities. In Proceedings of the 17th International ACM SIGACCESS Conference on Computers \& Accessibility. 69-76.

[36] Mark Johnson. 1987. The Body in the Mind: The Bodily Basis of Meaning, Imagination, and Reason. 1987. Chicago: $U$ of Chicago $P$ (1987).

[37] Brigitte Jordan and Austin Henderson. 1995. Interaction analysis: Foundations and practice. The journal of the learning sciences 4, 1 (1995), 39-103.

[38] Tamar Kalandadze, Courtenay Norbury, Terje Nærland, and Kari-Anne B Næss. 2018. Figurative language comprehension in individuals with autism spectrum disorder: A meta-analytic review. Autism 22, 2 (2018), 99-117.

[39] Anat Kasirer and Nira Mashal. 2014. Verbal creativity in autism: Comprehension and generation of metaphoric language in high-functioning autism spectrum disorder and typical development. Frontiers in human neuroscience 8 (2014), 615.

[40] Anat Kasirer and Nira Mashal. 2016. Comprehension and generation of metaphors by children with autism spectrum disorder. Research in Autism Spectrum Disorders 32 (2016), 53-63.

[41] Anat Kasirer and Nira Mashal. 2017. Comprehension and generation of metaphoric language in children, adolescents, and adults with dyslexia. Dyslexia 23, 2 (2017), 99-118.

[42] Christa Kelleher and Thorsten Wagener. 2011. Ten guidelines for effective data visualization in scientific publications. Environmental Modelling \& Software 26, 6 (2011), 822-827.

[43] Varsha Koushik and Shaun K Kane. 2019. "It Broadens My Mind": Empowering People with Cognitive Disabilities through Computing Education. In Proceedings of the 2019 CHI Conference on Human Factors in Computing Systems. ACM, 514.

[44] L Kraus, E Lauer, R Coleman, and A Houtenville. 2017. 2017 Disability Statistics Annual Report. Durham, NH: University of New Hampshire. (2017), 48.

[45] Werner Kuhn and Andrew U Frank. 1991. A formalization of metaphors and image-schemas in user interfaces. In Cognitive and linguistic aspects of geographic space. Springer, 419-434.

[46] Mukta Kulkarni and KV Gopakumar. 2014. Career management strategies of people with disabilities. Human Resource Management 53, 3 (2014), 445-466.

[47] George Lakoff. 2008. The Neural Theory of Metaphor. The Cambridge Handbook of Metaphor and Thought (2008), 17.

[48] George Lakoff and Mark Johnson. 2008. Metaphors we live by. University of Chicago press, USA.

[49] Sooyeon Lee, Bjorn Hubert-Wallander, Molly Stevens, and John M Carroll. 2019. Understanding and Designing for Deaf or Hard of Hearing Drivers on Uber. In Proceedings of the 2019 CHI Conference on Human Factors in Computing Systems. ACM, 529 .

[50] Mark L Lengnick-Hall, Philip M Gaunt, and Mukta Kulkarni. 2008. Overlooked and underutilized: People with disabilities are an untapped human resource. Human Resource Management: Published in Cooperation with the School of Business Administration, The University of Michigan and in alliance with the Society of Human Resources Management 47, 2 (2008), 255-273

[51] D. Leonardis, M. Solazzi, I. Bortone, and A. Frisoli. 2017. A 3-RSR Haptic Wearable Device for Rendering Fingertip Contact Forces. IEEE Transactions on Haptics 10, 3 (2017), 305-316.

[52] Leilah Lyons, Brian Slattery, Priscilla Jimenez, Brenda Lopez, and Tom Moher. 2012. Don't Forget about the Sweat: Effortful Embodied Interaction in Support of Learning. In Proceedings of the Sixth International Conference on Tangible, Embedded and Embodied Interaction (Kingston, Ontario, Canada) (TEI '12). Association for Computing Machinery, New York, NY, USA, 77-84. https://doi.org/10.1145/2148131.2148149

[53] Anna Macaranas, Alissa N Antle, and Bernhard E Riecke. 2012. Bridging the gap: attribute and spatial metaphors for tangible interface design. In Proceedings of the Sixth International Conference on Tangible, Embedded and Embodied Interaction. 161-168.

[54] David McNeill. 1992. Hand and mind: What gestures reveal about thought. University of Chicago press.

[55] Maurice Merleau-Ponty et al. 1964. The primacy of perception: And other essays on phenomenological psychology, the philosophy of art, history, and politics. Northwestern University Press.

[56] Vivian Genaro Motti. 2019. Designing emerging technologies for and with neurodiverse users. In Proceedings of the 37th ACM International Conference on the Design of Communication. 1-10.

[57] Anne Muth, Johannes Hönekopp, and Christine M Falter. 2014. Visuo-spatial performance in autism: a meta-analysis fournal of Autism and Developmental Disorders 44, 12 (2014), 3245-3263. 
[58] Jean Piaget. 1967. Logique et connaissance scientifique. (1967).

[59] Dave Randall, Richard Harper, and Mark Rouncefield. 2005. Fieldwork and Ethnography: A perspective from CSCW. Proceedings of EPIC 2005 (2005), 81-99.

[60] Michael B Ruef and Ann P Turnbull. 2002. The perspectives of individuals with cognitive disabilities and/or autism on their lives and their problem behavior. Research and Practice for Persons with Severe Disabilities 27, 2 (2002), 125-140.

[61] Lisa Schur, Douglas Kruse, and Peter Blanck. 2005. Corporate culture and the employment of persons with disabilities. Behavioral sciences \& the law 23, 1 (2005), 3-20.

[62] Lisa Schur, Douglas Kruse, Joseph Blasi, and Peter Blanck. 2009. Is disability disabling in all workplaces? Workplace disparities and corporate culture. Industrial Relations: A fournal of Economy and Society 48, 3 (2009), 381-410.

[63] Dorit Segal, Nira Mashal, and Lilach Shalev. 2015. Semantic conflicts are resolved differently by adults with and without ADHD. Research in developmental disabilities 47 (2015), 416-429.

[64] Lawrence Shapiro. 2019. Embodied cognition. Routledge.

[65] Kristen Shinohara and Jacob O Wobbrock. 2016. Self-conscious or self-confident? A diary study conceptualizing the social accessibility of assistive technology. ACM Transactions on Accessible Computing (TACCESS) 8, 2 (2016), 1-31.

[66] Kristen Shinohara, Jacob O Wobbrock, and Wanda Pratt. 2018. Incorporating social factors in accessible design. In Proceedings of the 20th International ACM SIGACCESS Conference on Computers and Accessibility. 149-160.

[67] Steve Silberman. 2015. Neurotribes: The legacy of autism and the future of neurodiversity. Penguin.

[68] Katta Spiel, Christopher Frauenberger, Os Keyes, and Geraldine Fitzpatrick. 2019. Agency of autistic children in technology research-A critical literature review. ACM Transactions on Computer-Human Interaction (TOCHI) 26, 6 (2019), 1-40.

[69] Patrizia Thoma and Irene Daum. 2006. Neurocognitive mechanisms of figurative language processing-evidence from clinical dysfunctions. Neuroscience \& Biobehavioral Reviews 30, 8 (2006), 1182-1205.

[70] Sharanjit Uppal. 2005. Disability, workplace characteristics and job satisfaction. International fournal of Manpower 26 , 4 (2005), 336-349.

[71] Arnold POS Vermeeren, Josje Van Beusekom, Marco C Rozendaal, and Elisa Giaccardi. 2014. Design for complex persuasive experiences: helping parents of hospitalized children take care of themselves. In Proceedings of the 2014 conference on Designing interactive systems. 335-344.

[72] Mila Vulchanova, David Saldaña, Sobh Chahboun, and Valentin Vulchanov. 2015. Figurative language processing in atypical populations: the ASD perspective. Frontiers in human neuroscience 9 (2015), 24.

[73] Jayne Wallace, John McCarthy, Peter C. Wright, and Patrick Olivier. 2013. Making Design Probes Work. In Proceedings of the SIGCHI Conference on Human Factors in Computing Systems (Paris, France) (CHI '13). Association for Computing Machinery, New York, NY, USA, 3441-3450. https://doi.org/10.1145/2470654.2466473

[74] Emily Q Wang and Anne Marie Piper. 2018. Accessibility in Action: Co-Located Collaboration among Deaf and Hearing Professionals. Proceedings of the ACM on Human-Computer Interaction 2, CSCW (2018), 180.

[75] Margaret Wilson. 2002. Six views of embodied cognition. Psychonomic bulletin \& review 9, 4 (2002), 625-636. https://doi.org/10.3758/BF03196322

\section{A EXAMPLES FROM TRANSCRIPT}

In Table 7 we report participants' remarks from the interviews that provide an example of what we coded using each schema.

Table 7. Embodied Schemata that we used and examples of participants' remarks

\begin{tabular}{|c|l|l|}
\hline Category & \multicolumn{1}{|c|}{ Schema } & Example \\
\hline FORCE & RESISTANCE & $\begin{array}{l}\text { but it makes you waste more time } \\
\text { working on two 20-page books - be- } \\
\text { cause there's also a break in between } \\
\text { it was more difficult because the } \\
\text { background is completely black and } \\
\text { we didn't have precise references }\end{array}$ \\
\hline
\end{tabular}

Proc. ACM Hum.-Comput. Interact., Vol. 5, No. CSCW2, Article 384. Publication date: October 2021. 


\begin{tabular}{|c|c|c|}
\hline & $\begin{array}{l}\text { COMPULSION } \\
\text { ENABLEMENT } \\
\text { COUNTERFORCE } \\
\text { BALANCE } \\
\text { MOMENTUM } \\
\text { DIVERSION } \\
\text { ATTRACTION }\end{array}$ & $\begin{array}{l}\text { for example when I finish at one } \\
\text { o'clock, if I happen to finish at one } \\
\text { o'clock, I bookmark the book so I re- } \\
\text { member the page where I finished } \\
\text { scanning for today } \\
\text { But is it always me you give these } \\
\text { books to? } \\
\text { he has this ability to solve problems } \\
\text { that the other guy does not have } \\
\text { no, it is not annoying, but it takes } \\
\text { up the time that you could use to do } \\
\text { more scans, optimize the time, and } \\
\text { reduce the workload. } \\
\text { but at the same time we should leave } \\
\text { them their own mind a little bit, be- } \\
\text { cause otherwise you risk the brain } \\
\text { falling asleep in a way and theynever } \\
\text { make the next small step forward } \\
\text { we have maybe a faster ability to } \\
\text { switch from one job to another, from } \\
\text { one solution to another, okay this is } \\
\text { the problem. Okay this is the solution } \\
\text { the anomaly, what deviates from the } \\
\text { knowledge that he has and that is } \\
\text { standardize } \\
\text { yes, this too. If I know he likes a cer- } \\
\text { tain one- sometimes I happened to } \\
\text { find a topic that I knew would be in- } \\
\text { teresting }\end{array}$ \\
\hline SPACE & $\begin{array}{l}\text { UP-DOWN } \\
\text { STRAIGHT } \\
\text { CONTACT } \\
\text { LEFT-RIGHT } \\
\text { VERTICALITY } \\
\text { CENTER }\end{array}$ & $\begin{array}{l}\text { the guys are autonomous on this part } \\
\text { and then they proceed with their } \\
\text { stages of work, which they know very } \\
\text { well } \\
\text { So it goes up more compared to a 20- } \\
\text { page book } \\
\text { to have a clear, well-framed image } \\
\text { that looks straight on the screen } \\
\text { I could do that myself, but I usually } \\
\text { ask someone else to do it } \\
\text { because you have to be careful that } \\
\text { it doesn't go down too much, that it's } \\
\text { centered, that it's not too far to the } \\
\text { right or too far to the left } \\
\text { it is okay to raise the bar } \\
\text { I think we've got to the heart of the } \\
\text { matter }\end{array}$ \\
\hline
\end{tabular}




\begin{tabular}{|c|c|c|}
\hline & NEAR-FAR & $\begin{array}{l}\text { if there are things to fix at this point, } \\
\text { then I send it to back them }\end{array}$ \\
\hline ATTRIBUTE & $\begin{array}{l}\text { STRONG-WEAK } \\
\text { WARM-COLD }\end{array}$ & $\begin{array}{l}\text { once I've finished with the books, I } \\
\text { send them back to K in the network } \\
\text { unit but I put them in the "Edited" } \\
\text { folder } \\
\text { however, gradually he must learn to } \\
\text { manage the anomaly, the diversity } \\
\text { I'm happy for the guys who did a } \\
\text { good job }\end{array}$ \\
\hline CONTAINMENT & $\begin{array}{l}\text { CONTAINER } \\
\text { CONTENT } \\
\text { IN-OUT }\end{array}$ & $\begin{array}{l}\text { I move it to my desktop folder } \\
\text { a book that has more than } 200 \text { pages } \\
\text { the idea of sinking my hands into } \\
\text { history }\end{array}$ \\
\hline MULTIPLICITY & $\begin{array}{l}\text { PART-WHOLE } \\
\text { COLLECTION }\end{array}$ & $\begin{array}{l}\text { from the beginning where I work in } \\
\text { collaboration with [name] who pro- } \\
\text { vides me with the material } \\
\text { which are made up of files, subfiles, } \\
\text { and documents } \\
\text { we have a shared folder on the desk- } \\
\text { top and I load the scanned images in } \\
\text { there } \\
\text { you always have to be very careful } \\
\text { about this because you risk splitting } \\
\text { documents and then taking up more } \\
\text { time to rename the whole file }\end{array}$ \\
\hline IDENTITY-SURFACE & MATCHING & $\begin{array}{l}\text { by moving the black cardboard un- } \\
\text { derneath that is used as a back- } \\
\text { ground } \\
\text { is a control during the processing to } \\
\text { make sure that everything comes out } \\
\text { quite precisely. I also fill out the form, } \\
\text { which means that I fill in the number } \\
\text { of the service request and the book } \\
\text { number basically and then, I decide } \\
\text { who to give them to, who scans are } \\
\text { precisely } \\
\text { I mainly deal with data entry }\end{array}$ \\
\hline LOCOMOTION & SOURCE-PATH-GOAL & $\begin{array}{l}\text { from the arrival of the material, } \\
\text { which is obviously checked, the de- } \\
\text { livery of the material to the guys, } \\
\text { which is made together, we decide } \\
\text { what books to do, one rather than the } \\
\text { other because here as well there is a } \\
\text { difference in the processing }\end{array}$ \\
\hline SCALE & MORE-LESS & $\begin{array}{l}\text { but it takes up the time that you could } \\
\text { use to do more scans }\end{array}$ \\
\hline
\end{tabular}




\begin{tabular}{|l|l|l|}
\hline PROCESS & \multicolumn{1}{|c|}{ CYCLE } & $\begin{array}{l}\text { after that, I need to scan these doc- } \\
\text { uments that are all in the same file } \\
\text { which are later sent where the data } \\
\text { entry is made, that is, where all these } \\
\text { files will be recorded following a cer- } \\
\text { tain type of criterion } \\
\text { a different way of processing infor- } \\
\text { ITERATION }\end{array}$ \\
& \\
&
\end{tabular}




\section{B FULL-SIZE VENN DIAGRAMS}

We report the full size version of the Venn Diagrams that we discussed in Section 5.2.1 (Figure 3).

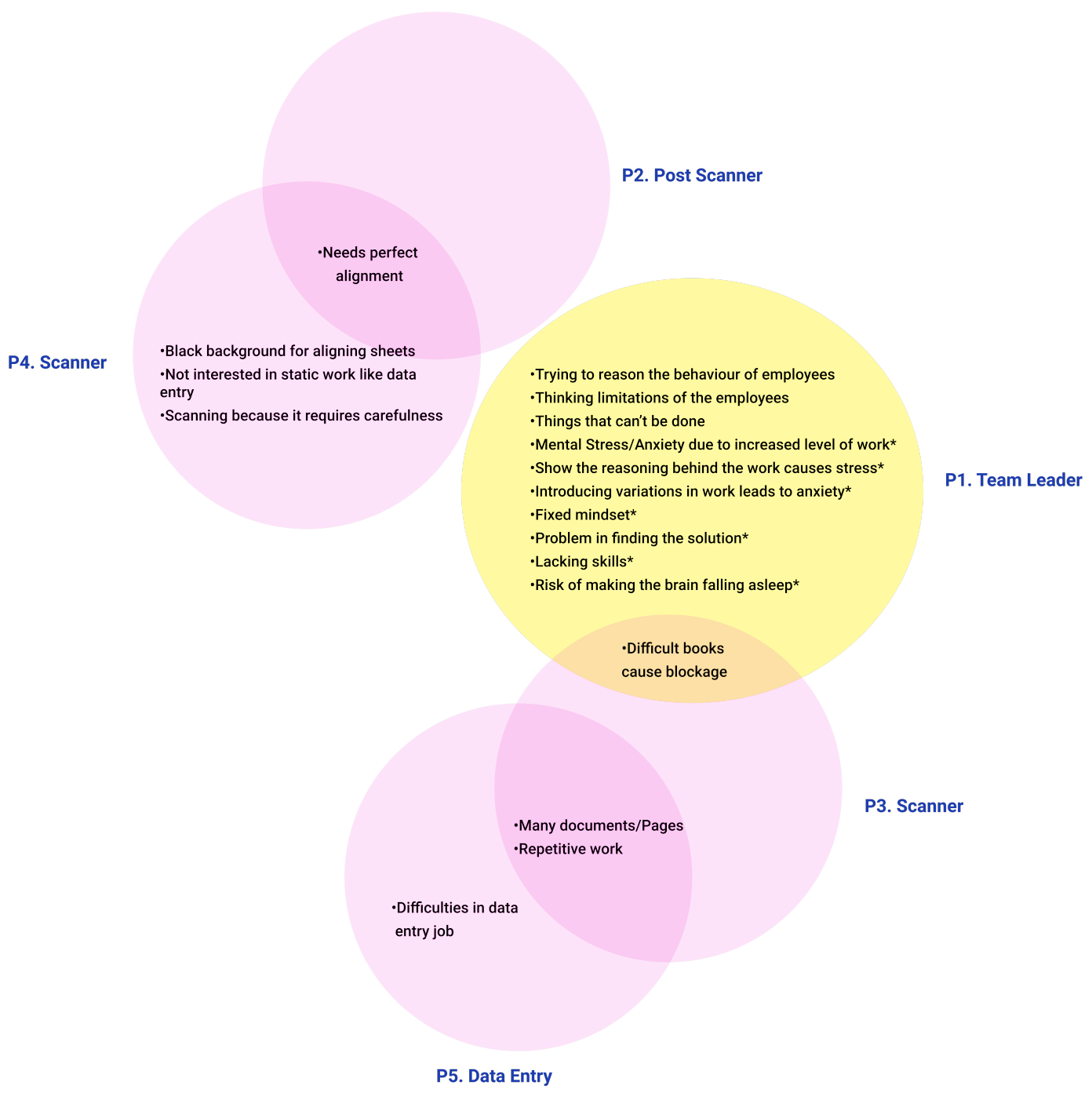

Fig. 4. Full-Size Venn Diagram for BLOCKAGE

Received October 2020; revised April 2021; accepted July 2021 
P4. Scanner

-Lining up sheet in order simulates accuracy
- Make easier for the reader

to read the

pages

-Software

allows to trim

it, straighten it

-Software

Marks

automatically

-Manage tasks

on own
P2. Post Scanner

P1. Team Leader

-Enabling to think of a solution on own

-Enablement by giving difficult books*

-Giving chance to outdo themselves*

-Introducing gradually*

-Discrimination made to enhance the strength of each one*

-Need to show reasoning*

-Gradually insert books*

\section{- Learned about it in practice}

\section{-Writing the measurement helps}

\section{P5. Data Entry}

\section{P3. Scanner}

Fig. 5. Full-Size Venn Diagram for ENABLEMENT 
P4. Scanner
-Wants the data-entry process to be automatic -Scanning the book again

\section{P2. Post Scanner}

$$
\begin{aligned}
& \text {-Support of a } \\
& \text { special } \\
& \text { software }
\end{aligned}
$$

automatic

\section{-Home-made} ruler helps

-By giving books choice to employees -Trying to think how employees think -Seeks solution independently* -Remove the Rigidity - Easier for mentor to find solutions to problem

-Answering the queries of Employees -Reduce the variability of tasks

\section{P1. Team Leader}

-Using Bookmarks

P3. Scanner

Fig. 6. Full-Size Venn Diagram for REMOVAL OF RESTRAINT 